\title{
Gender stereotyping in EFL grammar textbooks. A diachronic ap- proach
}

\author{
Marcin Lewandowski (Poznań)
}

\begin{abstract}
Gender stereotyping in educational materials (especially in EFL textbooks) has been a common theme in linguistic research (cf., e. g., Hellinger 1980; Porreca 1984; Freebody/Baker 1987; Sunderland 1994; Lee/Collins 2010). However, very little attention has been paid to the representation of men and women in EFL/ESL grammar textbooks; i. e. the way both genders are portrayed in constructed examples of usage and practice sentences. The present contribution is intended to fill this gap. The paper investigates the scope of gender stereotyping from a diachronic perspective: it seeks to demonstrate whether and how the images of men and women have changed following the dissemination of guidelines for non-sexist language and equal treatment of the two genders in English language educational materials. To this aim, two corpora have been compiled. The first one includes sentences derived from three EFL textbooks published in the $1970 \mathrm{~s}$ and $1980 \mathrm{~s}$, while the other one contains analogous data from three $21^{\text {st }}$ century titles. The contrastive analysis of the sentences in the two corpora across 11 semantic domains has found that the recently published grammar textbooks portray the two genders in a much less stereotyped way than the $20^{\text {th }}$ century course books.
\end{abstract}

\section{$1 \quad$ Introduction}

Stereotype as a theoretical construct has been frequently approached by linguists concerned with the relationship between language and gender. Kiełkiewicz-Janowiak and Pawelczyk (2006: 350-351), drawing on the views of Wright and Taylor (2003), argue that stereotypes, being ungrounded empirically, should not be viewed in terms of descriptions but interpretations that apply to social groups (not individuals). Stereotypes are also prescriptive in nature as they affect the perception of the surrounding world. Hence, "stereotypes, socially-imposed depersonalized constructs, affect actual individuals in creating and activating social expectations" (Kiełkiewicz-Janowiak/Pawelczyk 2006: 351). A similar point is made by Talbot (2003), for whom stereotyping as a practice lies at the heart of folklinguistics ${ }^{1}$, and "involves simplification, reduction, and naturalization" (ibd.: 470). Pauwels (1998: 79) views stereotypes as fixed images of individuals or groups. A specific stereotype is a constellation of physical, mental, cultural, and other features that tend to be isolated, exaggerated or oversimplified.

All of the above points apply to gender stereotypes - shared beliefs about what men and women are like - which are marked by yet another feature: masculinity and femininity are understood in dichotomous terms, constructing thus a binary opposition (cf. Mandal 2000: 14). Williams and Best (1990: 16), in their pioneering work on gender stereotyping across cultures, argue that

\footnotetext{
${ }^{1}$ As Talbot (2003: 472) defines the concept, "[f]olklinguistics is a term linguists sometimes use to refer to (generally) non-linguists' beliefs about language".
}

Linguistik online 68, 6/14 - http://dx.doi.org/10.13092/lo.68.1635

licensed under CC 3.0 
sex stereotypes ${ }^{2}$ operate at two separate levels: sex-role stereotypes, which include popular beliefs about the suitability of roles and activities for males and females, and sex-trait stereotypes, i. e. psychological or behavioral traits that are commonly believed to be characteristic of one gender rather than the other. Both subtypes are transmitted culturally in a multitude of ways: "[t]hrough the structure of the English language itself, through play activities, media depictions, the school environment, religious messages, and career models, the two sexes are depicted as differing widely in behavior and status" (Basow 1980: 62). Two institutions seem to be the most responsible for the transmission of gender stereotypes: the media and the educational systems (naturally, the degree of this influence varies cross-culturally). As regards the latter, gender bias is said to be reinforced by a wide range of educational resources.

Of all kinds of stereotyping in educational materials, gender stereotyping has received the greatest amount of attention in (socio)linguistic research. There are considerably fewer studies addressing stereotyping of ethnicity, elderly people or disability (Equal Opportunity Commission 2001). Gender stereotyping has come to be perceived as a manifestation of sexist practices (Pauwels 1998), i. e. practices "that contribute to demeaning or ignoring women (or men) or to stereotyping either sex; sexism is often not a matter of intention but of effect" (Linguistic Society of America 1996: 68).

An impressive amount of linguistic research to date has focused on gender stereotypes in various types of educational materials, primarily elementary school books and EFL textbooks (major findings will be discussed in the following section). The present paper has a narrower focus: it aims to demonstrate the degree of gender stereotyping in EFL grammar textbooks in a diachronic perspective. More specifically, it will attempt to answer the following questions:

1) How are men and women represented in English grammar textbooks? What are the major semantic domains in which male and female characters appear?

2) To what extent do these representations mirror gender stereotypes?

3) Are there any significant quantitative discrepancies in the representation of men and women resulting in the invisibility of either gender in some domains?

4) Is it legitimate to speak of any changes in all of the above areas in a diachronic perspective?

While many of the previous studies of linguistic sexism in educational resources have focused on the unfair portrayal of women or their invisibility, this paper will try to show that in actuality both genders can be affected by negative or positive stereotyping.

\section{Gender stereotyping in educational materials: an overview of research}

Research interest in gender bias in teaching resources dates back to the 1970s, when the first seminal studies on this topic were published (cf., e. g. Nilsen 1977; Hartman/Judd 1978; Hellinger 1980). Most of the contributions can be subdivided into two major thematic areas: sexism in elementary school books (cf., e. g., Nilsen 1977; Freebody/Baker 1987; Equal Opportunity Commission 2001; Law/Chan 2004; Karwatowska/Szpyra-Kozłowska 2005) and sexism in English language textbooks (cf., e. g., Hartman/Judd 1978; Hellinger 1980; Porreca 1984; Gupta/Lee Su Yin 1990; Sunderland 1994; Filak 2002; Ansary/ Babaii 2009; Lee/Collins 2010; Yang 2011). Of special relevance to the present study is also research on gender stereotyping in constructed syntactic examples in grammar teaching resources (cf. Sartori Stein 1978;

\footnotetext{
2 In a separate footnote, Williams and Best (1990: 43) say that while they are fully aware of the semantic differences between gender and sex, they use the two terms interchangeably. In this paper, the term gender will be predominantly employed unless referring to Williams and Best's concepts of sex-role and sex-trait stereotypes.
} 
Macaulay/Brice 1997; Amare 2007). This section will provide a brief overview of major findings underlying these studies.

The most obvious one seems to be the so-called quantitative imbalance in educational materials, which is related to the unequal representation of male and female characters: women are (sometimes significantly) outnumbered by men both textually and visually (in photos or drawings). ${ }^{3}$ On top of that, females tend to be shown as dependent on males as they are often referred to by their marital or family status. As Pauwels (1998: 34) puts it, "[t]he man (men or the male) is portrayed as the benchmark for all human beings; he is seen as the norm or reference-point", while "the woman is largely invisible". Such treatment of the genders has further implications for the male and female roles depicted in English teaching materials. Men are more frequently shown in professional settings than women. Most of the aforementioned studies have also found that males are stereotyped as working in a broader range of occupations, and are more likely to hold prestigious jobs and positions. Female characters in textbooks are usually portrayed as employed in lower status professions. ${ }^{4}$ Women feature much more prominently in domestic situations: they are involved primarily in childcare and household chores, such as cleaning, cooking or shopping. Men, by contrast, are stereotyped as more active and sporty, especially in outdoor settings. As regards the sex-trait stereotypes, females are shown as overly emotional, sentimental, timid, intellectually inferior to men, passive, and generally weak. They are also often described by physical attributes, such as appearance and clothing. A stereotypical male is a matter-of-fact, assertive and determined person, who is endowed with intellectual prowess and inclined to face challenges. Finally, what most, if not all, of the researchers agree upon is that through the unfair representation of men and women educational materials may contribute to perpetuating and spreading stereotyped views. This is because "[t]he value system of a course book can influence the perceptions and attitudes of learners" (Filak 2002: 10). However, more contemporary studies have demonstrated that the scope of gender stereotyping has in fact decreased and that recent textbooks contain fewer manifestations of sexist bias.

Central to this positive change is the growing awareness of the need for non-sexist educational materials, which has been brought about by several institutions and initiatives calling for the removal of sexist language and content from teaching resources in Anglophone countries. One of the first bodies promoting equal and fair treatment of the genders was the Women in TEFL group, set up in the UK in 1986, which later transformed into Women in EFL materials (cf., Florent/Walter 1989; Florent et al. 1994). The group argued strongly for challenging common stereotypes, for example by showing men and women in non-traditional occupations (i. e. typically associated with the domain of the other gender). Another initiative that deserves mention is a set of guidelines for non-sexist usage in linguistic texts issued by the Linguistic Society of America (LSA). Of the six recommendations proposed in the 1996 version, two refer explicitly to gender stereotyping:

3. Whenever possible, use terms that avoid sexual stereotyping. Such terms as server, professor, and nurse can be effectively used as gender neutral; marked terms like waitress, lady professor, and male nurse cannot.

5. In constructing example sentences, avoid gender-stereotyped characterizations.

(Linguistic Society of America 1996: 68)

\footnotetext{
${ }^{3}$ For example, in their study of gender representation in Australian children's readers, Freebody and Baker (1987) found that a total of 163 books contained approximately 2,000 names for boys and only 1,400 for girls. Lee and Collins' (2010) analysis of English language school textbooks in Australia and Hong Kong revealed that the percentage of male to female characters was 57.5 to 42.5 in the former country, and 53.5 to 46.8 in the latter.

${ }^{4}$ According to Porreca's (1984) content analysis of 15 EFL textbooks used in the United States in the 1980s, the ratio of working males to females was 6 to 1. Macaulay and Brice (1997: 809), in their study of constructed examples in syntax textbooks, found that women are five times less likely to have occupations than men.
} 
Finally, a few words need to be said about the work of the Equal Opportunity Commission established in 1996 in Hong Kong to combat various kinds of discrimination (gender, race, family status, disability, etc.). In 2001 it published an extensive report on discriminatory practices in educational materials (Equal Opportunity Commission 2001). Besides reviewing the state of research in the field, it postulated a multivariate approach to studying stereotypes in textbooks, which was based on five methodologies: content analysis, linguistic analysis, ethnographic analysis, survey analysis, and structured interviews (ibd.: 64).

\section{The present study}

\subsection{Corpus data and method}

It seems that gender stereotyping may even be more pervasive in EFL grammar textbooks than in integrated skills course books. As a result, it may also have a more powerful impact on book users. While doing exercises, learners focus more on purely grammatical aspects than on content, which is why gender stereotyping contained in grammar drills operates at a more subliminal level than in reading or listening material (Sartori Stein 1978: 123). It is hypothesized that constructed sentences may appeal to commonly shared attitudes, associations and experiences, which are grounded in stereotyped views of the world. Therefore, it is worthwhile exploring the scope of gender bias in constructed examples and follow-up practice sentences in EFL grammar textbooks as this topic has not received due attention in linguistic research.

The present paper draws on data from six UK-published grammar textbooks designed for advanced EFL learners. Three of them were issued in the 1970s and 1980s, that is before the introduction and promotion of the aforementioned anti-sexist guidelines, while the other three were published in the $2000 \mathrm{~s}$. The temporal divide is thus strictly related to one of the purposes of the study (more specifically, research question 4), which seeks to investigate whether increased awareness of gender equality in the $21^{\text {st }}$ century, coupled with various initiatives advocating change (eliminating sexist bias from English teaching materials), had a pronounced impact on the language and content of recent course books. In other words, the question is: to what extent do $21^{\text {st }}$ century English grammar textbooks mirror recommendations for balanced and non-stereotyped presentation of male and female characters?

The following is the list of EFL textbooks under analysis (ordered according to the year of publication). For the sake of further investigation, each title is followed by an abbreviation for easier reference.

1. Bywater, Frank V. (1971): A Proficiency Course in English. London: University of London Press. - TB1

2. Thomson, Audrey J./Martinet, Agnes W. (1983): A Practical English Grammar. Oxford: Oxford University Press. - TB2

3. Graver, Brian D. (1986): Advanced English Practice. Oxford: Oxford University Press. - TB3

4. Hewings, Martin (2001): Advanced Grammar in Use. A Self-Study Reference and Practice Book for Advanced Learners of English. With Answers. Cambridge: Cambridge University Press. - TB4

5. Vince, Michael/Sunderland, Peter (2003): Advanced Language Practice with Key. English Grammar and Vocabulary. Oxford: Macmillan Education. - TB5

6. Foley, Mark/Hall, Diane (2008): Longman Advanced Learners' Grammar. A Self-Study Reference \& Practice Book with Answers. Harlow: Longman. - TB6 
As regards data for analysis, from each textbook a set of 300 sentences containing either maleor female-gendered subjects has been derived. ${ }^{5}$ All of the sentences have been assigned to two separate corpora, which, for the sake of convenience, have been labeled old textbooks (OTs TB1, TB2, and TB 3) and new textbooks (NTs - TB4, TB5, and TB6). As can easily be calculated, each corpus totals 900 sentences that contain both male- and female-gendered subjects. The two corpora include both constructed examples of usage (or example sentences) that illustrate specific points of English grammar (e. g. the usage of verb tenses, clause types, modal verbs, articles, etc.), and sentences from follow-up exercises that are designed to provide practice for learners.

Prior to the analysis of gender stereotyping in the aforementioned titles, it is worthwhile looking at the quantitative data for male- and female-gendered subjects in the old and new textbooks. This information is provided in Table 1.

\begin{tabular}{|l|l|l|l|l|l|l|l|c|}
\hline & \multicolumn{4}{|l|}{ Old textbooks } & \multicolumn{3}{l|}{ New textbooks } \\
\cline { 2 - 8 } & TB1 & TB2 & TB3 & $\begin{array}{l}\text { Average } \\
\text { for OTs }\end{array}$ & TB4 & TB5 & TB6 & $\begin{array}{l}\text { Average } \\
\text { for NTs }\end{array}$ \\
\hline $\begin{array}{l}\text { Female } \\
\text { subjects }\end{array}$ & 28.2 & 27.0 & 12.3 & $\mathbf{2 2 . 5}$ & 50.3 & 48.2 & 43.0 & $\mathbf{4 7 . 2}$ \\
\hline $\begin{array}{l}\text { Male } \\
\text { subjects }\end{array}$ & 71.8 & 73 & 87.7 & $\mathbf{7 7 . 5}$ & 49.7 & 51.8 & 57.0 & $\mathbf{5 2 . 8}$ \\
\hline
\end{tabular}

Tab. 1: Ratio of female- to male-gendered subjects in the OTs and NTs (in \%).

The table reveals a significant quantitative change that occurred over the span of about 20 years. As can be seen, in the old textbooks, women are strongly underrepresented: on average, out of four gendered characters, only one is female. In TB3 this imbalance is extremely striking as for every feminine subject there are approximately seven masculine subjects, which makes female characters practically invisible. By contrast, in the case of the new textbooks, we can speak of a nearly proportional representation of female- and male-gendered subjects, with the latter outnumbering the former by a relatively small margin of 5.6\%. Interestingly, one corpus source, TB4, contains a slightly higher number of feminine subjects. It can thus be concluded that from the purely quantitative point of view, contemporary EFL grammar textbooks are superior to the 1970 s and 1980s titles in terms of balanced representation of both genders in the example and practice sentences.

\footnotetext{
5 An analysis of male- and female-gendered NPs in object position could well be the subject of a separate study. Macaulay and Brice's (1997: 800) investigation of gender stereotyping in syntax textbooks found that female NPs outnumber males in both direct and indirect object position.
} 


\begin{tabular}{|c|c|c|c|c|}
\hline \multirow[b]{2}{*}{ Semantic category } & \multicolumn{2}{|c|}{ Old textbooks } & \multicolumn{2}{|c|}{ New textbooks } \\
\hline & $\begin{array}{l}\text { Male- } \\
\text { gendered } \\
\text { subjects }\end{array}$ & $\begin{array}{l}\text { Female- } \\
\text { gendered } \\
\text { subjects }\end{array}$ & $\begin{array}{l}\text { Male- } \\
\text { gendered } \\
\text { subjects }\end{array}$ & $\begin{array}{l}\text { Female- } \\
\text { gendered } \\
\text { subjects }\end{array}$ \\
\hline Appearance & 7 & 20 & 5 & 9 \\
\hline Character traits & 71 & 22 & 48 & 37 \\
\hline Emotional states & 20 & 22 & 20 & 26 \\
\hline Employment & 105 & 11 & 77 & 65 \\
\hline Everyday duties & 4 & 23 & 3 & 4 \\
\hline Financial status & 36 & 4 & 13 & 11 \\
\hline Habits and addictions & 16 & 0 & 2 & 0 \\
\hline Intellectual activity & 77 & 11 & 43 & 36 \\
\hline Law and order & 38 & 0 & 26 & 9 \\
\hline Relationships & 16 & 21 & 27 & 25 \\
\hline Skills and hobbies & 66 & 13 & 62 & 51 \\
\hline Other & 250 & 57 & 159 & 156 \\
\hline Total $^{6}$ & 706 & 204 & 485 & 429 \\
\hline
\end{tabular}

Tab. 2: Distribution of male- and female-gendered subjects across the semantic categories in the OTs and NTs.

A far more intriguing task is to reconstruct the linguistic image of men and women in both old and new grammar textbooks in order to check to what extent it is affected by gender stereotyping and whether or not the NTs differ quantitatively and qualitatively from the OTs. The ensuing analysis will focus on the contexts in which female- and male-gendered subjects can be found. To this aim, the following eleven semantic categories (or domains) associated with subject occurrence have been delineated: appearance, character traits, emotional states, employment, everyday duties, financial status, habits and addictions, intellectual activity, law and order, relationships, and skills and hobbies. Most of the corpus sentences can be assigned to one of these categories (the ones that did not seem to fit in any of the domains have been allocated to the category "other"7). The quantitative data on the number of sentences including femaleand male-gendered subjects within each domain is presented in Table 2.

Through an overview of the aforementioned semantic categories, the following section presents and discusses the most important findings.

\subsection{The linguistic portrayal of men and women in ELF grammar textbooks across the semantic categories}

The discussion of findings in each domain will be preceded by sample sentences from the textbooks for the sake of illustration.

\section{Appearance}

1. She is very pretty and goes out a lot. (TB2)

2. Hilary has a most amazing hairstyle. (TB6)

3. Jim doesn't look well. He's lost a lot of weight. (TB4)

The semantic category of appearance does not seem to be frequently invoked in grammar textbooks. The quantitative data in both corpora confirms the findings of other researchers that in

\footnotetext{
6 The totals for male and female subjects do not add to 900 as both corpora contain a small number of sentences with both female- and male-gendered subjects (see ex. 25).

${ }^{7}$ Examples include such sentences as: He may come tomorrow (TB2) or She gave me the key to get in the house in case you were out (TB6).
} 
EFL materials women are more often described by their appearance than men. It has to be noted, however, that in the NTs, references to women's appearance are a little less than twice as common as in the OTs, which may be indicative of a smaller gender bias. Female characters are most frequently defined by their general attractiveness; overall, there are eight sentences including the adjective beautiful or its synonyms (there is only one such sentence in the NT corpus, though). The most prominent feature of women's appearance seems to be hair. Men, by contrast, are typically described by their height, weight and clothing.

\section{Character traits}

4. He solved the problem, as one might have expected. (TB3)

5. He gave orders that it should be done at once. (TB1)

6. At first he took us in by his stories and we tried to help him; but later we learnt that his stories were all lies. (TB2)

7. She enjoys being flattered. (TB1)

8. He stands up strongly for all his principles. (TB6)

9. Tim started to be respected (by his colleagues). (TB4)

10. She told me she is happy to help us. (TB5)

11. I can't stand the way she is always boasting about her wealthy parents. (TB5)

Character traits seem to be more associated with male-gendered subjects in both the OTs and NTs. It has to be noted, however, that the $21^{\text {st }}$ century textbooks contain a markedly higher proportion of female subjects in this domain than the 1970s and 1980s course books.

The discussion of gender stereotyping in this section will draw on the findings from one of the cross-cultural studies of sex-trait stereotypes by Williams and Best (1990) based on the concepts of psychological need theory proposed by Murray (1938), which posits that human personality can be conceived of in terms of psychological needs that direct individuals towards attaining specific objectives. Edwards (1954) identified 15 such needs and provided their definitions. The theory was further developed by Gough and Heilbrun (1980), who analyzed each of the 15 needs by linking it with adjectives from the Adjective Checklist (ACL) that were indicative or contraindicative of a given need. Williams and Best (1990: 119-146) in the study of gender stereotypes in 25 countries discovered a great deal of cross-cultural generality and found that the male stereotypes were associated with needs for dominance, autonomy, aggression, exhibition, achievement, and endurance, while the female stereotypes were correlated with needs for abasement, deference, succorance, nurturance, affiliation, and heterosexuality. The remaining three needs, i. e. change, order and intraception, were found to be linked with both women and men. The ensuing analysis will demonstrate how far these findings apply to gender portrayal in the OTs and NTs.

Of the 72 sentences including male-gendered subjects in the old textbooks, as many as 49 (69\%) can be semantically correlated with the six needs associated with the male stereotype. The most frequently invoked needs are achievement, aggression, exhibition and dominance. In the textbooks, men are depicted as goal-oriented, ambitious, strong-willed, forceful, self-righteous, sometimes autocratic, and industrious individuals, who are determined to achieve success. In doing so, they tend to elicit attention and pressure others to do things for them. Given the relatively small number of sentences with female-gendered subjects in the OTs, women are attributed fewer personality traits than men. However, of the 22 sentences including female characters in subject position, a similar proportion $(15$ sentences $-68 \%)$ can be linked with the six need scales constituting the female stereotype. The predominant one is succorance, i. e. the need "to solicit sympathy, affection, or emotional support from others" (Williams/Best 1990: 
122). Women are frequently depicted as self-centered, immature, emotional and whiny individuals. Judging by the corpus findings, in second place is the need for nurturance, which translates into trying to maintain good relationships with other people, avoiding conflict, and showing sympathy and support.

The new textbooks seem to present far less stereotyped images of men and women in terms of their character traits. Of the 48 sentences with male-gendered subjects in this domain, only 24 $(50 \%)$ can be linked with the needs typically associated with the male stereotype. For the sentences including female subjects, this proportion is even smaller: merely $40.5 \%$ (15 out of 37) of them can be said to reflect the female stereotype. As regards men, the most frequently invoked need in the corpus under investigation is endurance which, according to Gough and Heilbrun (1980: 9), subsumes such features as a sense of duty, diligence, and conservation of traditional values. Judging by the findings of Williams and Best (1990: 142), of all six "male" needs, endurance is the least strongly associated with the male stereotype. In second place is the need for dominance. As for the sentences with female-gendered subjects, the most commonly occurring needs are nurturance and exhibition, the latter of which, as stated above, is associated with the male stereotype. In the NT corpus there is a relatively high proportion of sentences $(37.8 \%)$ including female characters that exhibit stereotypically male features (besides exhibition, aggression, dominance and endurance). This would suggest that in their portrayal of women, the authors of recent textbooks have successfully managed to avoid gender stereotyping because women are portrayed as possessing cross-sex characteristics.

This is how Williams and Best conclude their cross-cultural study of sex-stereotypes based on the psychological need theory:

[I]t appears that men are generally considered to be decisive, strongly independent, and goal-oriented; to have strong leadership potential; to react aggressively when faced with opposition; and to have little nurturance or patience with others. [...] [W]omen are generally considered to be very sociable, interpersonallyoriented, considerate; and sympathetic to others; to respond with feelings and intuitions in most problemsolving situations; and to lack assertiveness and avoid conflict.

(Williams and Best 1990: 142-143)

While the above descriptions of stereotypical males and females largely fit most of the sentences in the old textbooks, they seem to be less applicable to gender representation in the new textbooks. In sum, it could thus be said that men and women are far more stereotyped in the OTs than in the NTs.

\section{Emotional states}

12. She was so upset that she couldn't help crying. (TB3)

13. He was so enraged that nothing I could say or do would pacify him. (TB3)

14. When she heard the results she was overjoyed. (TB4)

15. Neil was too embarrassed to bring up the question of who would pay. (TB5)

The semantic domain of emotional states is the first category in the OT corpus with an almost equal number of female- and male-gendered subjects. However, given the low visibility of women in the OTs in general (see Table 1), it can well be said that females are proportionally more frequently defined by emotions than males. For men, the most commonly experienced emotion seems to be anger ( $40 \%$ of the sentences can be linked with this state), which in extreme cases may be unleashed through aggressive behavior. By contrast, female-gendered subjects typically occur in the context of such emotional states as nervousness, apprehension, fear, and sympathy. Emotions are sometimes so overwhelming that they can trigger physiological reactions in women. There are five sentences with female characters who faint or break into tears (by comparison, there are no such examples including male subjects). The depiction of 
emotional states in the OTs is very much in line with the sex-trait stereotypes of the two genders discussed in the previous category. The stereotypically "female" emotions can be associated with the needs for succorance and nurturance whereas the 'male' emotion of anger can be related to the needs for aggression and dominance.

The above findings apply to the representation of male and female emotions in the NTs to a much smaller degree. In this corpus, emotional states are more frequently associated with female-gendered subjects. Women are defined by a broader spectrum of emotions. While they are still associated with apprehension, fear and sympathy (statistically, they are still more inclined to cry and faint than men), they also experience other states, such as joy and anger, the latter of which in the OT corpus is attributed primarily to men. Regarding the male-gendered subjects, they also occur in contexts associated with a wide range of emotions, including not only anger but also fear, anxiety, apprehension, and embarrassment. It could again be argued that the authors of recent grammar textbooks have, to a large extent, managed to avoid gender stereotyping.

\section{Employment}

16. When Mr Brown retired as Managing Director his eldest son replaced him. (TB1)

17. The solicitor talked his client out of taking legal action. (TB3)

18. The girls who serve in the shop are the owner's daughters. (TB2)

19. After his illness the Minister continued in his office though he was no longer up to the work (TB2).

20. The doctor can see you at six; he can't see you before then as he's too busy. (TB6)

21. The school she is head of is closing down. (TB4)

22. Margaret was slow at school, but she went on to be Prime Minister. (TB5)

As the data from the OT corpus shows, women are significantly outnumbered by men in professional settings (by a ratio of nearly 1:10). Similar disproportions have been observed in other studies of gender bias in teaching resources (see footnote 4 for examples). Moreover, as Macaulay and Brice (1997: 809) rightly argue, "[w]hen females do have jobs, these jobs are generally of a lower status than the ones males have". Men, in turn, have been found to be employed in a wide range of occupations, including high-status (or prestigious) jobs. In other words, women lose out to men on both horizontal (the range of occupations) and vertical (the status of the profession) dimensions of occupational roles (Equal Opportunity Commission 2001: 60). These findings have also been confirmed by the corpus data from the present study. Of the barely 11 female job holders, five have unspecified work, two work as salesgirls, while the remaining four are employed as a teacher, a nurse, a personal assistant (secretary), and an actress. By contrast, of the 105 male job holders, 41 have unspecified work, while the others are employed in as many as 26 professions, the most popular of which are army officer, teacher, prime minister, minister, journalist, actor, lawyer, and doctor. Another count has found that none of the working females holds an executive position whereas 10 males are employed in managerial posts. Within the employment domain, a subcategory of political occupations has been delineated. Its analysis has confirmed that politics is perceived as the province of men, with 17 male characters involved in this area. Women are totally invisible: none of them works in a political profession.

In the NTs the two genders are portrayed much more fairly and equally. Females are no longer underrepresented in professional settings even though they are still outnumbered by males by approximately 10\% (65 female subjects vs. 77 male subjects). Regarding the range of jobs available to both genders, women are employed in 19 occupations whereas men in 20 . The 
horizontal dimension, however, still shows a slight male bias as women still tend to work in a little less prestigious jobs. With 24 women doing unspecified work, the most popular female occupations are: teacher ( 6 women employed in this occupation), actress (4), personal assistant (3), and shopkeeper (3). The figures for male job holders are as follows: 29 have unspecified work, six work as presidents, five as army officers, four as doctors, three as prime ministers, academics, and actors. While females are finally present in the world of politics, they are considerably outnumbered by men (there are four women employed in political occupations as opposed to $13 \mathrm{men}$ ). On the other hand, significant improvement needs to be noted with regard to the representation of the two genders in executive positions as there is an equal number of men and women employed in managerial posts.

\section{Everyday duties}

23. She spent the afternoon cleaning the spare room and putting some kind of order in it. (TB1)

24. Women are expected to like housework. (TB2)

25. Sally was reading to the children while Kevin was washing up.(TB4)

While in the old textbooks women are practically invisible in professional settings, the reverse phenomenon occurs in the sphere of everyday chores, where females outnumber males by a proportion of approximately $6: 1$. The quantitative data from the OT corpus confirms the findings of other researchers (e. g. Lee/Collins 2010: 128) that women are cast much more frequently than men in purely domestic roles. Female characters are much more likely to perform such duties as: cleaning, washing the dishes, cooking or shopping. Needless to say, the strong presence of women in domestic settings contributes to their stereotypical image in the OTs.

The new textbooks contain very few examples in this category (there are six times fewer female-gendered subjects than in the OTs), and at the same provide a far more balanced representation of the two genders. As ex. 23 demonstrates, men can also be involved in stereotypically "female" duties.

\section{Financial status}

26. He has a chateau in Provence which I have stayed at. (TB1)

27. John offered me a lot of money for the car. (TB4)

28. Helen augmented her small salary by making shrewd share dealings. (TB5)

The financial status category embraces all references to money and possessions owned, bought or sold. In the OT corpus, male-gendered subjects prevail over female-gendered ones by a proportion of 9:1. It is almost solely men who earn, spend, invest or inherit money. It is also men who buy, own and sell status symbols, such as cars, houses or expensive gadgets. Women are hardly ever mentioned in such contexts, which means that they are virtually invisible in this domain.

Male-centeredness is non-existent in recent textbooks, which, overall, contain far fewer references to financial status. In the NT corpus, both genders are more or less equally represented. However, the qualitative analysis of the data has found that men are represented as wealthier or having more possessions than women.

\section{Habits and addictions}

29. A few years ago he was an alcoholic, but he has managed to give up drinking now. (TB1)

30. He knows that he smokes too much but says that he can't get out of the habit. (TB2) 
There are only two habits and addictions mentioned in EFL grammar textbooks: tobacco use and alcohol consumption. Both are male-monopolized activities since either corpus is lacking in any sentences with female-gendered subjects. It could even be inferred that women never smoke or drink alcohol. Thus, it seems legitimate to say that in this semantic domain it is males who are (negatively) stereotyped as addicted to tobacco and alcohol. ${ }^{8}$

References to drinking and smoking are eight times more frequent in the OT corpus. Evidently, both habits have become taboo topics in recent textbooks whose authors may have been advised by the publishers to refrain from exposing socially undesirable behaviors. ${ }^{9}$

\section{Intellectual activity}

31. The woman-teacher is not making much headway with her Italian studies. (TB1)

32. John was so brilliant that no-one else in the class got any chance of distinguishing himself. (TB1).

33. He graduated at Yale University. (TB3).

34. He'll be taking up his place at university in July. (TB4).

35. Pauline is in demand as an after-dinner speaker. (TB5).

This domain includes references primarily to such activities as: reading, writing, public speaking and school or university education. The OT corpus findings confirm the views of Macaulay and Brice (1997: 807-809), who delineated a similar category, that intellectual activity is the male domain. For every sentence with a female-gendered subject in this category, there are seven sentences including male subjects. Moreover, a number of sentences stereotype women as unsuccessful in their endeavors (see ex. 31). As a matter of fact, out of 11 female characters, only one can be said to excel in her field. While there are several sentences that depict men as doing poorly in some areas, about half of the examples portray males as intellectually successful individuals. Hence, it can be concluded that the OT corpus data reflects a strong male bias.

As was the case with most of the previous categories, the NTs present a much more balanced portrayal of the two genders in this domain. Females, who are not significantly outnumbered by males, are involved in a wide range of intellectual activities, including those which used to be stereotypically attributed to males. Women are cast in the roles of public speakers, experts or polyglots.

\section{Law and Order}

36. He told me he was planning the perfect murder. (TB1)

37. The man was sent to prison for six months, having been found guilty of fraud. (TB3)

38. The escaped prisoner couldn't find anywhere to hide so she gave herself up. (TB5)

Judging by the OT corpus data, it can be inferred that men are the sole perpetrators of violence, who often get into trouble with the law (the corpus does not contain any sentences with femalegendered subjects in this category). There are several sentences depicting males as involved in various crimes, such as: murder, burglary, theft, blackmail, fraud or smuggling. It is also only men who stand trials and run or hide away from the police. It can be argued that in this category, men are targets of negative stereotyping.

\footnotetext{
8 According to Karwatowska and Szypyra-Kozłowska (2005: 126-128), alcohol addiction is one of the few semantic domains in contemporary Polish lexis marked by discriminatory sexist practices towards men, which is reflected by an abundance of terms denoting male alcoholics or drunkards (there are hardly any terms referring to women).

${ }^{9}$ Other topics which, in the publishers' view, should be avoided in EFL materials are drugs, sex, and violence (Waring 2003).
} 
These findings largely hold true for the NT books. However, the corpus contains fewer examples in this semantic domain, which, as argued in footnote 9, probably results from the publishers' guidelines for authors to refrain from controversial or taboo topics such as violence. Interestingly, women are no longer totally invisible in this category even if they are outnumbered by men by a proportion of 1:3. In fact, they are sometimes cast in mold-breaking roles, as in ex. 38 , which clearly undermines the female stereotype (a prison fugitive is stereotypically male).

\section{Relationships}

39. A hen-pecked husband is one who always agrees to do what his wife wants. (TB1)

40. His father warned him not to let others lead him astray. (TB3)

41. His wife begged him not to take any risks. (TB2)

42. Dad would always help us with our maths homework. (TB6)

43. Tom asked Jane out, but she turned him down. (TB5)

The domain of relationships is one of the few categories in the OT corpus where female-gendered subjects outnumber male-gendered ones. This is strictly related to the social role attributed to women, who are more visible in domestic settings than men. As a result, according to the corpus data, females are twice more frequently identified as wives than males as husbands. Moreover, in nearly all examples they are referred to as somebody's wife whereas men as husbands appear on their own (never as somebody's husband) in generalizing statements, as in the highly sexist example 39 . Women are also more often mentioned as mothers, who are involved in childcare or upbringing. By contrast, men, when defined as fathers, never take care of children but act as authority figures for them. Female participants occur more commonly in the context of romantic relationships, which confirms Macaulay and Brice's view (1997: 813) that "females are being stereotyped as the romantic and relationship-oriented gender".

The NTs present less stereotyped images of men and women, with both genders having equal quantitative representation. Interestingly, within the corpus, there are hardly any explicit references to wives and husbands in subject positions. Mothers are still mentioned more commonly than fathers, and they are still more frequently involved in childcare and upbringing. However, fathers are no longer completely invisible in this role (see ex. 42). Nor are they stereotyped as authoritative and demanding individuals. Both male and female characters are equally depicted as involved in romantic relationships.

\section{Skills and hobbies}

44. He could drive the car when he was eighteen. (TB3)

45. On Sundays he used to get up early and go fishing. (TB2)

46. My neighbour is practising the violin; she usually practises at about this time. (TB2)

47. Jane plays tennis well, but she'll never be (a) Steffi Graf. (TB4)

48. Jane stopped to check the oil level in the engine. (TB5)

In the OT corpus, men are associated with different skills and hobbies five times more frequently than women. ${ }^{10}$ Male participants are depicted as having a broad range of interests, hobbies, and skills, such as fishing, hunting, traveling, playing instruments, and do-it-yourself, to name just a few. Women are practically associated with only two skills: playing musical instruments and dancing (more than half of the female characters are engaged in these activities).

\footnotetext{
${ }^{10}$ A similar point was made by Lee and Collins (2010) in their analysis of visual representation of the two genders in Australian and Hong Kong English language textbooks. Men were found to be more frequently engaged in various sorts of activities, such as playing, relaxing, social and personal activities.
} 
Within this domain, two subcategories have been distinguished: sports and cars. The quantitative analysis has shown that men are engaged in sports activities seven times more frequently than women (29 male-gendered subjects as opposed to only 4 female-gendered ones). As far as the latter subcategory is concerned, driving a car appears to be a male-monopolized activity: women drivers are totally invisible in the OT corpus.

The NTs once again reflect a move towards gender equality. Even though males are still more frequently associated with various skills and hobbies, female characters are engaged in a far broader range of activities than in the OTs. Besides playing musical instruments, they are keen on painting, craftwork, do-it-yourself or hunting. The latter two are considered to be "stereotypically" male activities, which once again indicates that women in the NTs are more frequently cast in mold-breaking roles. Women are also far more engaged in sports activities: there are 23 female characters playing sports as compared to 31 male participants. Car driving is no longer a male-monopolized activity even though men still outnumber women as drivers by a ratio of 1.4:1. Sentence 48 is yet another example that NT writers are eager to challenge the female stereotype by involving women in activities that are traditionally attributed to men.

The above presentation of the study's findings can be best concluded by taking a synthetic look at all semantic domains in order to see how the portrayal of women and men has evolved over the years. Table 3 shows the proportional representations of male- and female-gendered subjects across the domains under analysis.

\begin{tabular}{|l|c|c|c|c|}
\hline \multirow{2}{*}{ Semantic category } & \multicolumn{2}{|l|}{ Old textbooks } & \multicolumn{2}{l|}{ New textbooks } \\
\cline { 2 - 5 } & $\begin{array}{l}\text { Male- } \\
\text { gendered } \\
\text { subjects }\end{array}$ & $\begin{array}{l}\text { Female- } \\
\text { gendered } \\
\text { subjects }\end{array}$ & $\begin{array}{l}\text { Male- } \\
\text { gendered } \\
\text { subjects }\end{array}$ & $\begin{array}{l}\text { Female- } \\
\text { gendered } \\
\text { subjects }\end{array}$ \\
\hline Appearance & 1.0 & 9.8 & 1.0 & 2.1 \\
\hline Character traits & 10.1 & 10.8 & 9.9 & 8.6 \\
\hline Emotional states & 2.8 & 10.8 & 4.1 & 6.1 \\
\hline Employment & 14.9 & 5.4 & 15.9 & 15.1 \\
\hline Everyday duties & 0.6 & 11.3 & 0.6 & 0.9 \\
\hline Financial status & 5.1 & 2.0 & 2.7 & 2.6 \\
\hline Habits and addictions & 2.3 & 0.0 & 0.4 & 0.0 \\
\hline Intellectual activity & 10.9 & 5.4 & 8.9 & 8.4 \\
\hline Law and order & 5.4 & 0.0 & 5.4 & 2.1 \\
\hline Relationships & 2.3 & 10.3 & 5.6 & 5.8 \\
\hline Skills and hobbies & 9.3 & 6.4 & 12.8 & 11.9 \\
\hline Other & 35.4 & 27.9 & 32.8 & 36.4 \\
\hline
\end{tabular}

Tab. 3: Percentage shares of the semantic categories in the representations of men and women in the OTs and NTs.

As regards the OT corpus, it appears that men are most frequently defined by employment since nearly $15 \%$ of all male-gendered subjects can be associated with this category. Male subjects are also commonly employed in such areas as intellectual activity, character traits as well as skills and hobbies. The most popular domains where female-gendered subjects occur are (in the order of decreasing significance): everyday duties, character traits, emotional states, relationships, and appearance. Evidently, the OT authors portray men and women in markedly different 
ways (only the character traits category ranks high for both female and male subjects), linking them with different semantic categories. It would even be fair to say that in the areas where males have a strong presence, females often have very few representatives or are practically invisible. The same holds true for female-dominated categories in which male subjects are rarely employed (e. g. the most popular "female" domain, everyday duties, is the least common category for male subjects). These quantitative findings are indicative of a highly stereotypical representation of men and women in the old EFL grammar textbooks.

The analysis of the data for the NTs in Table 3 reveals different images of the two genders. The most striking finding is that the hierarchy of the four most popular domains is identical for both feminine and masculine subjects. Both female and male participants are most frequently defined by employment, skills and hobbies, character traits, and intellectual activity. The quantitative disparities are in fact marginal: even if men tend to be more commonly identified with the four aforementioned categories, the mean difference is a mere $0.9 \%$ (by comparison, the mean difference for the same categories in the OT corpus is 4.3\%). It appears then that in recent textbooks, men and women are defined in more or less equal proportions by the same semantic categories. Major quantitative differences can only be found in less frequently invoked domains. Female characters are still more commonly associated with emotional states and appearance while male participants tend to be more frequently linked with law and order. Overall, it can be said that the NTs depict the two genders much more fairly and in a less stereotyped manner than the OTs.

\section{Conclusion}

Referring back to the first research question, it can be concluded that the major semantic domains in which female and male characters are represented in EFL grammar textbooks include employment, skills and hobbies, intellectual activity, and character traits. However, it needs to be emphasized that due to the overall low presence of females in the 1970s and 1980s books (in some categories bordering on invisibility), women are significantly underrepresented in the first three areas in the OTs.

The above analysis has found that the old grammar textbooks in many ways reflect genderstereotyped views. In general, women are depicted as the inferior gender since they are frequently cast in subsidiary roles: they tend to be defined by appearance, marital status (or family situation), and involvement in domestic chores. As a consequence of that, females are poorly represented in the world of labor: if they happen to have a job, it is usually a medium or lowstatus one. They also seem to be portrayed as less intellectually gifted and affluent than men. As regards character traits and emotional states, the analysis has revealed a number of correspondences between the images of men and women in the OTs and the cross-cultural female and male stereotypes, as investigated by Williams and Best (1990). Men are defined primarily by employment, intellectual activity as well as hobbies and skills. They are often depicted as mentally strong and independent high achievers. On the other hand, males are sometimes negatively stereotyped as being in trouble with the law, exhibiting aggressive behavior, and suffering from smoking or alcohol addiction.

Most of these findings do not hold true for the NTs, in which males and females are far less gender-stereotyped and more equally represented across the semantic domains. The study has shown, for example, that both men and women are attributed cross-gender character traits and emotions. Women are employed in a far broader range of occupations (including those that used to be traditionally reserved for men); they are also no longer shown as solely involved in domestic work, and are almost as frequently as men associated with intellectual activity and various skills and hobbies. However, a slight male bias persists in some areas: women are still more rarely depicted as working in high-status jobs or involved in politics, and seem to be less 
frequently associated with possessions and wealth. By contrast, male characters are outnumbered by female ones in the semantic domains of appearance and emotional states. In sum, even if the NTs still contain some examples of mild or covert gender stereotyping, they definitely reflect a significant move towards gender egalitarianism. Moreover, they are totally free from manifestations of blatant sexism, which can be found in the OTs (see ex. 39).

Finally a few words need to be said about methods of combating instances of gender stereotyping in EFL materials. According to Florent and Walter (1989), in constructing EFL materials, it is very difficult to be completely liberated from some kind of gender bias. They also claim that challenging the persisting gender stereotypes in a radical way (e. g. by casting males and females in mold-breaking roles) may confound learners, who usually have some preconceived ideas about gender roles. A different view is voiced by Lee and Collins (2010: 134), who regard teaching materials as agents for social change as "textbooks should promote the kind of social situation to which our communities aspire". In the light of these divergent stands, it would be interesting to investigate, in a separate study, learners' perceptions of gender roles and traits reflected in EFL grammar textbooks.

\section{References}

Amare, Nicole (2007): "Where Is She? Gender Occurrences in Online Grammar Guides". Research in the Teaching of English 42/2: 163-187.

Ansary, Hassan/Babaii, Esmat (2003): "Subliminal Sexism in Current ESL/EFL Textbooks". In: Odebunmi, Akin/Arua, Arua E./Sailal, Arimi (eds): Language, Gender and Politics. A Festschrift for Yisa Kehinde Yusuf. Lagos, Concept Publications: 177-190.

Basow, Susan A. (1980): Sex-Role Stereotypes. Traditions and Alternatives. Monterey, CA: Brooks/Cole Pub. Co.

Bywater, Frank V. (1971): A Proficiency Course in English. London: University of London Press.

Edwards, Allen L. (1954): Manual. Edwards Personal Preference Schedule. New York: Psychological Corporation.

Equal Opportunity Commission (2001): "Stereotypes in Textbooks and Teaching Materials in Hong Kong. A Literature Review". http://www.hurights.or.jp/pub/hreas/ 7/09HongKong.pdf, accessed January 2, 2014.

Filak, Aleksandra (2002): "Men and Women between Cultures. Gender Stereotypes in EFL Coursebooks in Poland". NeoLit Online 1/2: 1-49. http://jedrzejko.eu/pobierz pdf.php?id=12\&art, accessed January 2, 2014.

Florent, Jill/Walter, Catherine (1989): "A Better Role for Women in TEFL". ELT Journal 43/3: 180-184.

Florent, Jill et. al. (1994): "Case Study 1. On Balance. Guidelines for the Representation of Women and Men in English Language Teaching Materials". In: Sunderland, Jane (ed.): Exploring Gender. Questions and Implications for English Language Education. New York, Prentice Hall: 112-120.

Foley, Mark/Hall, Diane (2008): Longman Advanced Learners' Grammar. A Self-Study Reference \& Practice Book with Answers. Harlow: Longman.

Freebody, Peter/Baker, Carolyn (1987): "The Construction and Operation of Gender in Children's First School Books". In: Pauwels, Anne (ed.): Women and Language in Australian and New Zealand Society. Sydney, Australian Professional Publications: 80-107.

Gough, Harrison G./Heilbrun, Alfred B. (1980): The Adjective Check List Manual. Paolo Alto, CA: Consulting Psychologists Press.

Graver, Brian D. (1986): Advanced English Practice. Oxford: Oxford University Press.

Gupta, Anthea F./Lee Su Yin, Ameline (1990): "Gender Representation in English Language Textbooks Used in the Singapore Primary Schools". Language and Education 4/1: 29-50. 
Hartman, Pat L./Judd, Eliot L. (1978): "Sexism and TESOL Materials". TESOL Quarterly 12: 383-393.

Hellinger, Marlis (1980): "'For Men Must Work, and Women Must Weep'. Sexism in English Language Textbooks Used in German Schools". Women's Studies International Quarterly 3: 267-275.

Hewings, Martin (2001): Advanced Grammar in Use. A Self-Study Reference and Practice Book for Advanced Learners of English. With Answers. Cambridge: Cambridge University Press.

Karwatowska, Małgorzata/Szpyra-Kozłowska, Jolanta (2005): Lingwistyka ptci. Ona i on w języku polskim. Lublin: Wydawnictwo Uniwersytetu Marii Curie-Skłodowskiej.

Kiełkiewicz-Janowiak, Agnieszka/Pawelczyk, Joanna (2006): "Gender Stereotypes in Language Use: Polish and English". In: Dziubalska-Kołaczyk, Katarzyna (ed.): IFAtuation. A Life in IFA. A Festschrift for Professor Jacek Fisiak on the Occasion of His 70 th Birthday. Poznań, Wydawnictwo Naukowe UAM: 349-383.

Law, Kenneth W. K./Chan, Annie H. N. (2004): "Gender Role Stereotyping in Hong Kong's Primary School Chinese Language Subject Textbooks". Asian Journal of Women's Studies 10: 49-69.

Lee, Jackie F. K./Collins, Peter (2010): "Construction of Gender. A Comparison of Australian and Hong Kong English Language Textbooks". Journal of Gender Studies 19/2: 121-137.

Linguistic Society of America (1996): "The LSA Guidelines for Nonsexist Usage". LSA Bulletin December/1996: 8. http://www.linguisticsociety.org/files/The\%20LSA\%20Guide lines\%20for\%20Nonsexist\%20Usage.pdf, accessed January 2, 2014.

Macaulay, Monica/Brice, Colleen (1997): "Don't Touch My Projectile. Gender Bias and Stereotyping in Syntactic Examples". Language 73/4: 798-825.

Mandal, Eugenia (2000): Podmiotowe i interpersonalne konsekwencje stereotypów zwiazanych z ptcia. Katowice: Wydawnictwo Uniwersytetu Śląskiego.

Murray, Henry A. (1938): Explorations in Personality. New York: Oxford University Press.

Nilsen, Alleen P. (1977): "Sexism in Children's Books and Elementary Classroom Materials". In: Nilsen, Alleen P. et. al. (eds.): Sexism and Language: Urbana, IL, National Council of Teachers of English: 161-179.

Pauwels, Anne (1998): Women Changing Language. London/New York: Longman.

Porreca, Karen L. (1984): "Sexism in Current ESL Textbooks". TESOL Quarterly 18/4: 704724.

Sartori Stein, Anneliese (1978): "Cultural Chauvinism in Foreign-Language Textbooks". In: Freudenstein, Reinhold (ed.): The Role of Women in Foreign-Language Textbooks. Bruxelles, AIMAV: 123-136.

Sunderland, Jane (1994): "Introduction to Quadrant II". In: Sunderland, Jane (ed.): Exploring Gender. Questions and Implications for English Language Education. New York, Prentice Hall: 55-66.

Talbot, Mary (2003): "Gender Stereotypes. Reproduction and Challenge". In: Holmes, Janet/Meyerhoff, Miriam (eds.): The Handbook of Language and Gender: Oxford, Blackwell Publishing Ltd: 468-486.

Thomson, Audrey J./Martinet, Agnes W. (1983): A Practical English Grammar. Oxford: Oxford University Press.

Vince, Michael/Sunderland, Peter (2003): Advanced Language Practice with Key. English Grammar and Vocabulary. Oxford: Macmillan Education.

Waring, Rob (2003): "Writing a Graded Reader". http://www.robwaring.org/papers/various/ Writing_graded_reader.doc, accessed January 2, 2014.

Williams, John E./Best, Deborah L. (1990): Measuring Sex Stereotypes. A Multination Study. Newbury Park, CA/London/New Delhi: Sage Publications. 
Wright, Stephen C./Taylor, Donald M. (2003): "The Social Psychology of Cultural Diversity. Social Stereotyping, Prejudice and Discrimination". In: Hogg, Michael A./Cooper, Joel (eds.): The SAGE Handbook of Social Psychology. London, Sage: 432-457.

Yang, Chi Ch. R. (2011): "Gender Representation in a Hong Kong Primary English Textbook Series. The Relationship between Language Planning and Social Policy". Current Issues in Language Planning 12/1: 77-88. 